reperfusion and application of hot packs. The stomach, colon, and liver were reduced, and the hernia was repaired. The patient's condition improved clinically, and the chest $\mathrm{x}$-ray showed a well-expanded left lung. The patient was discharged on the seventh day.

Congenital diaphragmatic hernias result from failure of fusion of the multiple developmental components of the diaphragm. Bochdalek hernias occur posterolaterally at the lumbocostal junctions of the diaphragm. Only a few Bochdalek hernias are first discovered in adulthood. ${ }^{1}$ Bochdalek hernias occur on the left side in approximately $80 \%$ of cases. ${ }^{2}$ In older children and adults, a Bochdalek hernia may manifest as an asymptomatic chest mass. The differential diagnosis includes mediastinal or pulmonary cyst or tumor, pleural effusion, or empyema. Symptoms, when present, are due to herniation of the stomach, omentum, colon, or spleen.

A Bochdalek diaphragmatic hernia that was initially misdiagnosed as pneumonia with massive pleural effusion has been described. ${ }^{3}$ A report of a 76-year-old man with a right-sided Bochdalek hernia who was admitted acutely with dyspnea has been described ${ }^{4}$ computed tomography of the abdomen revealed marked elevation of the right hemidiaphragm caused by herniation of the colon. The prevalence of the incidentally diagnosed asymptomatic posterior diaphragmatic hernias in the age groups 50 to 59 years, 60 to 69 years, and 70 to 79 years was $10.5 \%$,
$13.7 \%$, and $20.3 \%$, respectively, in a prospective study of chest computed tomography. ${ }^{5}$

\section{CONCLUSIONS}

Laparoscopic and thoracoscopic repair of the Bochdalek hernia have been described. ${ }^{6,7}$ There were no statistically significant differences in complications, additional related operative procedures, use of prosthetic patch, recurrence, length of stay, or postoperative mortality between the thoracoscopic repair and open repair groups. ${ }^{7}$

\section{References}

1. Guttman FM, Laberge J-M. Congenital diaphragmatic hernia. In: Nyhus LM, Condon RE, eds. Hernia. Philadelphia: Lippincott; 1989:694.

2. Langer JC. Congenital diaphragmatic hernia. Chest Surg Clin North Am. 1998;8 295

3. Chiu CC, Yeh HF, Chiu TF. Bochdalek diaphragmatic hernia masquerading as pneumonia-a rare cause of non-traumatic hemothorax. Am J Emerg Med. 2009;27:252. e1-2.

4. Kavanagh DO, Ryan RS, Waldron R. Acute dyspnoea due to an incarcerated rightsided Bochdalek's hernia. Acta Chir Belg. 2008;108:604-6.

5. Kinoshita F, Ishiyama M, Honda S, Matsuzako M, Oikado K, Kinoshita T, et al Late-presenting posterior transdiaphragmatic (Bochdalek) hernia in adults: prevalence and MDCT characteristics. $J$ Thorac Imaging. 2009;24:17-22.

6. Palanivelu C, Rangarajan M, Rajapandian S, Amar V, Parthasarathi R. Laparoscopic repair of adult diaphragmatic hernias and eventration with primary sutured closure and prosthetic reinforcement: a retrospective study. Surg Endosc. 2009;23: 978-85. Epub 2009 Mar 14

7. Cho SD, Krishnaswami S, Mckee JC, Zallen G, Silen ML, Bliss DW. Analysis of 29 consecutive thoracoscopic repairs of congenital diaphragmatic hernia in neonates compared to historical controls. J Pediatr Surg. 2009;44:80-6.

\title{
"Freezing" the left ventricular outflow tract for homograft reconstruction in aortic root endocarditis
}

\author{
Daniel Pereda, MD, and Soon J. Park, MD, Rochester, Minn
}

Root replacement with cryopreserved homografts is frequently used to treat active endocarditis. To alleviate concerns with tissue fragility, it would be desirable to stabilize the left ventricular outflow tract (LVOT) and aortic annulus. We report the case of a patient with active endocarditis who underwent placement of an aortic root homograft

\footnotetext{
From the Division of Cardiovascular Surgery, Mayo Clinic, Rochester, Minn. Disclosures: Authors have nothing to disclose with regard to commercial support. Received for publication April 29, 2010; accepted for publication May 5, 2010; available ahead of print July 5, 2010.

Address for reprints: Soon J. Park, MD, Mayo Clinic, Division of Cardiovascular Surgery, 2001 st St SW, Rochester, MN 55905 (E-mail: park.soon@mayo.edu). J Thorac Cardiovasc Surg 2011;141:301-3 $0022-5223 / \$ 36.00$

Copyright (c) 2011 by The American Association for Thoracic Surgery doi:10.1016/j.jtcvs.2010.05.005
}

protected by a novel technique of "freezing" the LVOT with a circumferential continuous suture and a sizer.

\section{CLINICAL SUMMARY}

A 35-year-old man with a history of intravenous drug abuse and aortic valve replacement with a mechanical prosthesis 7 years previously for a bicuspid valve with severe regurgitation was transferred to our institution with the diagnosis of complicated prosthetic valve endocarditis. The diagnosis was made after the incidental finding of multiple embolic infarcts in brain, liver, kidney, and spleen after a motor vehicle accident. Serial blood cultures grew methicillin-sensitive Staphylococcus aureus, and transesophageal echocardiography revealed extensive perivalvular involvement with periannular abscess and cavitation on the mitroaortic curtain. 


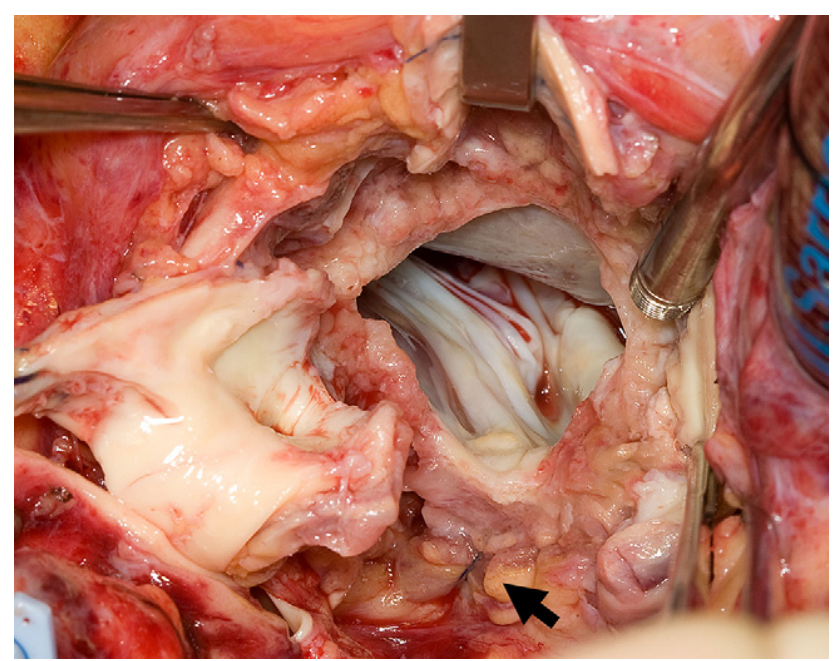

FIGURE 1. LVOT after débridement. Arrow shows the repaired roof of the left atrium.

The operation was performed through a median resternotomy, with cardiopulmonary bypass and hypothermia at $28^{\circ} \mathrm{C}$. There were vegetations on the surface of the prosthesis and an extensive aortic root abscess with purulent content. It tracked into the ventricular septum and the roof of the left atrium. The entire aortic annulus was débrided of infected tissue and phlegmon (Figure 1). A small portion of the roof of the left atrium had to be excised and later reconstructed.

To increase the consistency of the remaining LVOT and aortic annulus, we placed a circumferential continuous suture in the LVOT with a 3-0 polypropylene suture and tied it over a $27-\mathrm{mm}$ sizer (Figure 2) to "freeze" the LVOT, preventing its continuous distention and contraction throughout the cardiac cycle. The root replacement was then performed with a $28-\mathrm{mm}$ cryopreserved aortic homograft (CryoLife Inc, Kennesaw, Ga) with direct reimplantation of the coronary buttons. All suture lines were treated with Tisseel (Baxter Inc, Deerfield, Ill). The patient was easily weaned from cardiopulmonary bypass, and transesophageal echocardiography showed a normal functioning homograft with a gradient of $10 \mathrm{~mm} \mathrm{Hg}$. Crossclamp and cardiopulmonary bypass times were 167 and 200 minutes, respectively. After an unremarkable recovery, the patient was discharged in good condition back to his referring hospital on postoperative day 3 .

\section{DISCUSSION}

Root replacement with cryopreserved homografts in active endocarditis has proven good results in terms of mortality and durability, with excellent hemodynamic performance and very low rates of reinfection. ${ }^{1,2}$ These features of cryopreserved homografts, together with their exceptional reconstructive properties after extensive débridement, have made them for many surgeons the substitute of choice for complex aortic endocarditis with subvalvular or perivalvular involvement. ${ }^{2}$

Homograft tissue is fragile, however, and pseudoaneurysm formation is a well-known complication during follow-up. ${ }^{3}$ Reoperation after homograft root replacement is a surgical challenge that carries important mortality and morbidity risks. ${ }^{4}$ We propose this technique of LVOT "freezing" to avoid these risks. Stabilization of the LVOT anastomotic site might be particularly important in situations in which the structural integrity of the aortic annulus has been lost to an extensive abscess. Otherwise, the fragile homograft tissue at the anastomotic site may not be able to endure the mechanical stress of dynamic LVOT diameter change during the cardiac cycle. This technique reinforces the anastomosis, preventing continued dilation and contraction and transmission of shear forces into the suture line between the fragile remnants of the débrided LVOT and the friable allograft tissue, potentially reducing the distention and tissue tearing that may lead to bleeding complications, dehiscence, and late pseudoaneurysm formation. Also, by tying the circular suture around a universal sizer, we can easily downsize the LVOT diameter to a desired
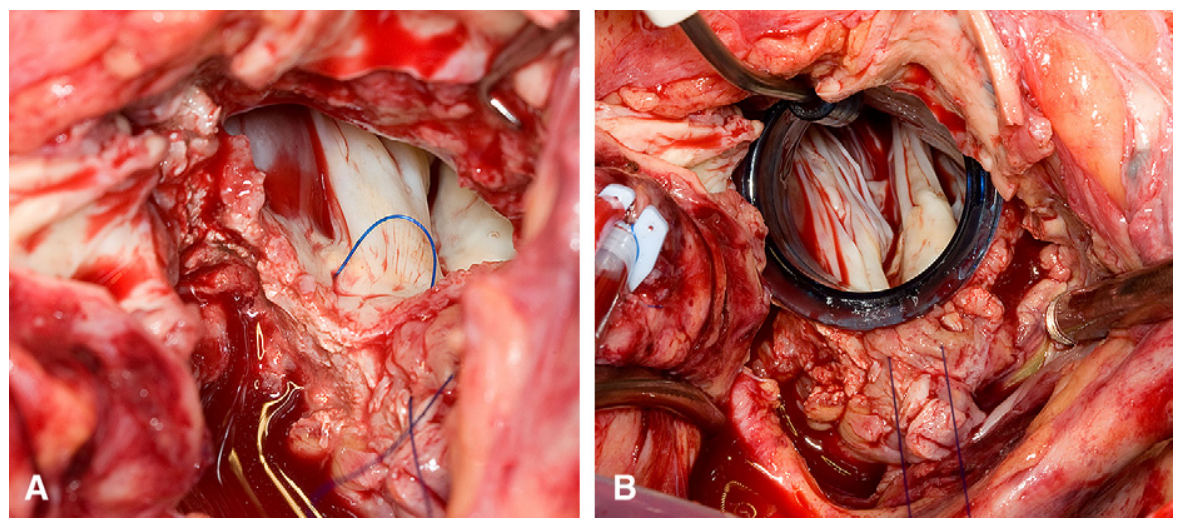

FIGURE 2. A, Circular 3-0 polypropylene suture around left ventricular outflow tract. B, Suture tied around 27-mm sizer to "freeze" left ventricular outflow tract to desired diameter. 
dimension. This facilitates precise homograft size selection that takes into account graft size availability and recipient's ascending aortic diameter.

We found this technique to be very simple. Without adding significant crossclamp time, it has the potential to prevent complications that may be extremely difficult to repair after completion of the coronary buttons and distal anastomoses, when the proximal suture is first tested under realistic pressure and hemodynamic conditions. This is to the best of our knowledge the first report of this technique.

\section{References}

1. Yankah AC, Pasic M, Klose H, Siniawski H, Weng Y, Hetzer R. Homograft reconstruction of the aortic root for endocarditis with periannular abscess: a 17-year study. Eur J Cardiothorac Surg. 2005;28:69-75.

2. Musci M, Weng Y, Hubler M, Amiri A, Pasic M, Kosky S, et al. Homograft aortic root replacement in native or prosthetic active infective endocarditis: twenty-year single-center experience. J Thorac Cardiovasc Surg. 2010;139:665-73.

3. Oechslin E, Carrel T, Ritter M, Attenhofer C, von Segesser L, Kiowski W, et al Pseudoaneurysm following aortic homograft: clinical implications? Br Heart J. 1995;74:645-9.

4. Nowicki ER, Pettersson GB, Smedira NG, Roselli EE, Blackstone EH, Lytle BW Aortic allograft valve reoperation: surgical challenges and patient risks. Ann Thorac Surg. 2008;86:761-8. e2.

\title{
Straight bronchial stent placement across the right upper lobe bronchus: A simple alternative for the management of airway obstruction around the carina and right main bronchus
}

\author{
Yun-Hen Liu, MD, Yi-Cheng Wu, MD, Ming-Ju Hsieh, MD, and Po-Jen Ko, MD, Tao-Yuan, Taiwan
}

\section{Supplemental material is available online.}

A variety of techniques have been described for stent placement in airway obstruction around the carina and the right main bronchus. These techniques use the silicone Y-stent, the double Y-stent, or an open "window" toward the right upper lobe (RUL) ${ }^{1,2}$ However, there is still no clear consensus on the optimal management of patients in this category. We describe 2 patients who were successfully treated with the simplified straight Dumon stent (Novatech, Grasse, France).

\section{CLINICAL SUMMARY}

Patient 1 was a 33-year-old woman with a 7-year history of pulmonary tuberculosis. The patient had stenosis at the right main bronchus (RMB) and RUL bronchus and underwent multiple bronchoscopic interventional procedures (electrocoagulation and cryosurgery) without clinical improvement.

\footnotetext{
From the Department of Surgery, Chang Gung Memorial Hospital at Linko, Chang Gung University, TaoYuan, Taiwan.

Disclosures: Authors have nothing to disclose with regard to commercial support.

Received for publication Feb 11, 2010; accepted for publication June 6, 2010; available ahead of print July 15, 2010

Address for reprints: Po-Jen Ko, MD, Department of Surgery, Chang Gung Memorial Hospital and Chang Gung University, No. 5, Fu-Shing Street, Guei-Shan Shiang,

Tao-Yuan, Taiwan 333, R.O.C (E-mail: foreverairmail@gmail.com).

J Thorac Cardiovasc Surg 2011;141:303-5

$0022-5223 / \$ 36.00$

Copyright (C) 2011 by The American Association for Thoracic Surgery doi:10.1016/j.jtcvs.2010.06.015
}

Chest radiographs showed complete collapse of the right lung. Bronchoscopy revealed a cuticular membrane lesion $(1 \mathrm{~cm})$ below the carina that completely obstructed the RMB. Computed tomography revealed severe distortion and narrowing of the RUL bronchi. Under general anesthesia, the blunt tips of Dumon scopes were used to manipulate and dilate the obstructed region of the RMB. The obstructed segment of bronchus was then opened, the normal airway size was achieved, and a number 14 Dumon stent $(14 / 30 \mathrm{~mm})$ was introduced over the stricture segment to maintain a patent airway. Chest roentgenogram showed good lung expansion with atelectasis of the RUL on the day after surgery. At 2 weeks post-surgery, the bronchoscopy revealed a good and patent airway without granulation and stent migration. The improvement in respiratory performance was dramatic after stent placement. The patient was discharged in good condition 2 days after surgery and was able to resume work 2 weeks after surgery. The patient did not experience any further complications related to stent placement during the follow-up period at 17 months post-stent placement (Figures 1 and E1, $A$ ).

Patient 2 was an 82-year-old man with right main bronchial chondroid hamartoma who presented with a 3-month history of progressive cough and intermittent shortness of breath. Chest computed tomography scans showed a masslike lesion in the right hilar region with distortion and stricture of the right main and RUL bronchi. Bronchoscopic evaluations revealed a mass that obstructed the RMB and extended along the RMB and down into the intermediate bronchus. The patient refused to undergo conventional airway reconstruction. With insertion of the rigid bronchoscope under general anesthesia, the stricture over the trachea was 